\title{
Modelo agrometeorológico-espectral de estimativa de rendimento de grãos de trigo no Rio Grande do Sul ${ }^{1}$
}

\author{
Amanda Heemann Junges ${ }^{2}$, Denise Cybis Fontana ${ }^{3}$
}

\section{RESUMO}

Este trabalho teve como objetivo construir uma regressão linear múltipla, empregando variáveis agrometeorológicas e espectrais, para estimativa de rendimento de grãos de trigo, em municípios pertencentes à região de atuação da Cooperativa Cotrijal (norte do Rio Grande do Sul). Para isso, foram empregados dados de rendimento (1991 a 2006), dados agrometeorológicos mensais (1991 a 2006) e dados espectrais (imagens NDVI/MODIS, 2000 a 2006). Foi analisada existência de aumento significativo no rendimento de grãos, decorrente da incorporação de novas tecnologias (tendência tecnológica). Para escolha das variáveis independentes da regressão linear, foi analisada a correlação dos dados agrometeorológicos e espectrais com os dados de rendimento. Definidas as variáveis, foi construída uma regressão linear múltipla de estimativa de rendimento de grãos de trigo. Os resultados mostraram que não houve aumento significativo no rendimento de grãos de trigo da Cotrijal, no período analisado. Foram escolhidas as seguintes variáveis independentes para construção da regressão linear múltipla: precipitação pluvial (outubro), índice de dano por geadas (setembro), graus-dia (acumulados de maio a outubro) e índice de vegetação por diferença normalizada (integrado de junho a outubro). As regressões lineares múltiplas apresentaram resultados satisfatórios, com erros de estimativa inferiores a 10\%, na maior parte dos anos analisados. As características de precisão, fácil execução e baixo custo das regressões apontaram para possibilidade de uso conjunto de dados agrometeorológicos e espectrais, na estimativa de rendimento de grãos de trigo. Mais estudos são necessários para verificação dos resultados dos modelos, quando da incorporação de uma série mais longa de dados espectrais.

Palavras-chave: Índice de vegetação por diferença normalizada, índice de geada, precipitação pluvial, graus-dia.

\section{ABSTRACT}

\section{Agrometeorological-spectral model to estimate wheat yield in the State of Rio Grande do Sul, Brazil}

This study aimed to estimate the wheat yield within the Cotrijal Cooperative's operational area (northern Rio Grande do Sul), using spectral and meteorological variables. Yield data (1991-2006), monthly agrometeorological data (1991-2006) and spectral data (NDVI/MODIS, 2000-2006) were used in the analyses. The existence of a significant increase in grain yield due to the incorporation of new technologies was analyzed (technology trend). The choice of the independent variables was based on the analysis of the correlation between yield and spectral and meteorological data. For the multiple linear regression of grain yield estimation the following independent variables were used: rainfall (October), frost damage index (September), degree-days (accumulated from May to October) and NDVI (integrated from June to October). The multiple linear regressions showed satisfactory results with estimation errors below $10 \%$, in most examined years. Accuracy, easy implementation and low cost of regressions pointed to the possibility of joint use of spectral and agrometeorological data in estimating wheat yield in the Cotrijal region. However, further studies are recommended to verify the results of the generated models when incorporating a longer series of spectral data.

Key words: Normalized difference vegetation index, frost index, pluvial precipitation, degree-day.

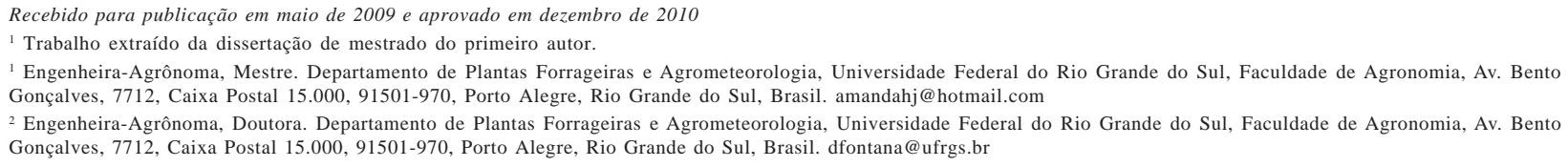




\section{INTRODUÇÃO}

Modelos agrometeorológicos permitem estimativas de rendimento de grãos anteriores à data de colheita dos cultivos, constituindo-se, assim, uma importante ferramenta para previsão de safras agrícolas (Carmona \& Berlato, 2002).

Os modelos agrometeorológicos fundamentam-se na relação estatística entre variáveis dependentes, que deverão ser estimadas (por exemplo, rendimento de grãos ou desenvolvimento fenológico), e variáveis meteorológicas (precipitação pluvial, temperatura do ar e radiação solar), de acordo com uma regressão linear múltipla. A regressão linear múltipla visa estabelecer a importância relativa e a magnitude do efeito das variáveis independentes sobre a variável dependente (Moreira, 2008).

Mota (1998) determinou os seguintes indicadores agrometeorológicos e coeficientes de correlação do rendimento de grãos de trigo no Rio Grande do Sul, para o período de 1986 a 1995: duração do período de molhamento foliar em outubro $(-0,92)$, insolação total em setembro $(0,93)$, índice de dano por geadas em setembro $(-0,89)$ e número de dias com precipitação pluvial em novembro $(0,86)$. Tais indicadores foram considerados as variáveis de entrada do modelo agrometeorológico, que apresentou erro de aproximadamente $11 \%$ na estimativa de rendimento de grãos de trigo do Estado.

É importante salientar que modelos agrometeorológicos, por serem construídos a partir de dados coletados em estações meteorológicas, apresentam limitação quanto à representatividade espacial dos resultados. Nesse sentido, informações geradas por técnicas de sensoriamento remoto têm sido empregadas na previsão de safras agrícolas, tanto no mapeamento de área cultivada, quanto na estimativa de rendimento.

A incorporação de variáveis espectrais ao modelo agrometeorológico pode torná-lo mais eficiente e condizente com o ambiente em que se dá o desenvolvimento das culturas agrícolas, o qual se mostra dinâmico, em termos espaciais e temporais (Rizzi, 2004). Em modelos agrometeorológico-espectrais, as variáveis agrometeorológicas expressam a influência das condições meteorológicas no crescimento e desenvolvimento das plantas. As variáveis espectrais, por sua vez, expressam, além das condições meteorológicas, a influência das práticas de manejo, dos cultivares, da localização espacial e de demais elementos não incluídos no componente agrometeorológico, na determinação do rendimento final (Melo et al., 2008).

A variável espectral pode ser representada, por exemplo, por índices de vegetação. Resultantes da combinação dos valores de reflectância em dois ou mais intervalos de comprimento de onda, os índices possuem relação com a quantidade e o estado da vegetação presente em uma determinada área da superfície terrestre (Rizzi, 2004). $O$ índice de vegetação mais utilizado em pesquisas relacionadas com a dinâmica da cobertura vegetal é o Índice de Vegetação por Diferença Normalizada (NDVI, do inglês Normalized Difference Vegetation Index), que pode ser obtido, por exemplo, de imagens do sensor MODIS (do inglês Moderate Resolution Imaging Spectroradiometer). Imagens NDVI/MODIS são bastante úteis em estudos de áreas agrícolas, devido à larga faixa de imageamento, resolução espectral (largura e número de bandas), própria ao monitoramento da vegetação, e série contínua de imagens desde o ano 2000 (Huete et al., 2002). Além disso, as imagens são distribuídas gratuitamente aos usuários, corrigidas atmosférica e geometricamente, na forma de composições de 16 dias, minimizando problemas decorrentes da cobertura de nuvens.

Modelos agrometeorológicos-espectrais de estimativa de rendimento foram propostos, por exemplo, para as culturas da soja (Rizzi, 2004; Melo et al., 2008) e arroz (Klering, 2007), no Rio Grande do Sul; soja, no Paraná (Sugawara, 2001); café, em Minas Gerais (Rosa, 2007) e cana-de-açúcar, em São Paulo (Rudorff \& Batista, 1990).

Atualmente, no Estado do Rio Grande do Sul, assim como no Brasil, é empregado o modelo tradicional de previsão de safras, via aplicação de questionários a produtores, cooperativas e órgãos de assistência técnica. Este processo envolve tempo, custos elevados e aspectos subjetivos, os quais podem ser minimizados pelo uso de tecnologias de sensoriamento remoto, sistemas de informações geográficas e modelos agrometeorológicosespectrais (Deppe et al., 2007). Neste contexto, acreditase que a elaboração de modelos agrometeorológicosespectrais, de estimativa de rendimento de grãos de trigo, pode melhorar a eficiência e a dinâmica das estimativas agrícolas, em âmbito regional.

Sendo assim, o presente trabalho teve como objetivo elaborar uma equação de regressão linear múltipla, empregando variáveis agrometeorológicas e espectrais, para estimativa de rendimento de grãos de trigo em municípios localizados ao norte do Estado do Rio Grande do Sul.

\section{MATERIAL E MÉTODOS}

A área de estudo compreendeu treze municípios localizados ao norte do Rio Grande do Sul, tradicional região produtora de trigo no Estado. Os treze municípios pertencem à área de atuação da Cooperativa Tritícola Mista Alto Jacui Ltda - Cotrijal: Almirante Tamandaré do Sul, Carazinho, Colorado, Coqueiros do Sul, Ernestina, Lagoa dos Três Cantos, Não-Me-Toque, Nicolau Vergueiro, Passo Fundo, Saldanha Marinho, Santo Antônio do Planalto, Tio Hugo e Victor Graeff. Estes municípios estão inseri- 
dos na regional Passo Fundo, definida administrativamente pela Associação Riograndense de Empreendimentos de Assistência Técnica e Extensão Rural - EMATER/RS.

A região está localizada, de acordo com a classificação climática de Köppen, na Zona Climática Fundamental Temperada (C), clima fundamental úmido (f), variedade específica subtropical (Cfa), com precipitação pluvial bem distribuída durante o ano e temperatura média do mês mais quente superior a $22^{\circ} \mathrm{C}$ (Köppen, 1948).

O período indicado para semeadura de trigo é da segunda quinzena de maio à primeira de julho (Fronza et al., 2008). O desenvolvimento fenológico das lavouras, na região de estudo, foi baseado no calendário de acompanhamento de lavouras de trigo da regional EMATER/RS Passo Fundo. Assim, na média das safras agrícolas de 2003 a 2006, a maior porcentagem da área cultivada com trigo encontrava-se em estádio de desenvolvimento vegetativo na segunda quinzena de julho; em florescimento na segunda quinzena de setembro; em processo de enchimento de grãos na primeira quinzena de outubro e em maturação fisiológica na primeira quinzena de novembro. A colheita, na maior parte da área, ocorreu a partir da segunda quinzena de novembro.

Neste trabalho, foram utilizados dados de rendimento médio de grãos de trigo, provenientes do Levantamento Sistemático da Produção Agrícola (dados de 1990 a 2005), ou disponibilizados pela Cotrijal (dado referente ao ano 2006).

Foi analisada a existência de tendência tecnológica no rendimento de grãos de trigo da região de estudo, no período de 1990 a 2006. O termo tendência tecnológica, introduzido em modelagem em 1975 (Braga, 1995), refere-se a aumentos anuais significativos no rendimento de grãos, que são decorrentes da incorporação de novas tecnologias pelos produtores (cultivares ou sistemas de manejo, por exemplo). Esse aumento deve ser retirado dos valores de rendimento empregados na elaboração de modelos agrometeorológicos-espectrais. Neste trabalho, para verificação da existência de aumento significativo no rendimento, foi construída uma equação de regressão linear simples, na qual o rendimento de grãos é a variável dependente e o tempo (anos), a variável independente. A significância do coeficiente linear (b) foi verificada pelo teste-t, a 1\% de significância estatística, considerando-se como hipótese nula o coeficiente ser igual a zero (não houve incremento significativo no rendimento de grãos no período).

Também foram empregados dados meteorológicos diários, de 1991 a 2006, obtidos da estação meteorológica, localizada no município de Passo Fundo e pertencente à rede de estações do $8^{\circ}$ Distrito do Instituto Nacional de Meteorologia - $8^{\circ}$ DISME/INMET. Foram analisadas as variáveis meteorológicas originais: insolação (horas), pre- cipitação pluvial (mm), número de dias com precipitação pluvial, umidade relativa do ar (\%) e temperaturas do ar $\left({ }^{\circ} \mathrm{C}\right)$ máxima, média e mínima; bem como as seguintes variáveis meteorológicas derivadas: número de dias com temperatura mínima do ar inferior a $0^{\circ} \mathrm{C}$; graus-dia calculados com temperaturas basais de $0{ }^{\circ} \mathrm{C}$ e $4,5^{\circ} \mathrm{C}$; índice de dano por geada (IG); índice de dano por precipitação pluvial na colheita e quociente fototermal (Cunha et al., 2005).

Os dados meteorológicos diários foram utilizados no cálculo dos valores mensais (maio a novembro) de cada uma das variáveis (originais ou derivadas). Para precipitação pluvial, número de dias com precipitação pluvial e graus-dia também foram determinados os valores referentes à soma dessas variáveis nos períodos de maio a novembro, junho a novembro e maio a outubro.

Os dados espectrais corresponderam a imagens do sensor MODIS, produto NDVI (MOD13), obtidas do banco de imagens do Projeto Geosafras, junto ao Centro Estadual de Pesquisa em Sensoriamento Remoto e Meteorologia (CEPSRM-UFRGS). As imagens (combinações de 16 dias), utilizadas foram referentes ao período que abrangeu o ciclo da cultura de trigo na região de estudo, ou seja, de maio a novembro, para os anos de 2000 a 2006.

Os dados de NDVI foram extraídos por meio da metodologia de máscaras de cultivo, proposta por Fontana et al. (2007). Para elaboração das máscaras de cultivos, foram empregadas imagens de máximo NDVI anual (junho a setembro), máximo NDVI histórico (construída com as imagens de máximo NDVI anual, de 2000 a 2006) e imagens de mínimo NDVI anual (abril e maio). Posteriormente, foram construídas imagens de diferença, as quais corresponderam à subtração das seguintes imagens: máximo NDVI histórico e mínimo NDVI anual. As imagens diferença buscaram identificar, a cada ano, as áreas nas quais ocorreram as maiores variações temporais do índice, pois estas corresponderam, possivelmente, a lavouras de cereais de inverno. Todo processamento das imagens NDVI/MODIS foi realizado no programa computacional Envi 4.2.

Após a extração dos valores de NDVI, referentes a lavouras de cereais de inverno, foram calculados o NDVI médio mensal (maio a novembro), a soma do NDVI (maio a novembro) e o NDVI integrado (cálculo da área abaixo da curva descrita pelos valores mensais do NDVI, de maio a novembro).

As variáveis meteorológicas originais e derivadas e as variáveis espectrais (NDVI) foram correlacionadas com o rendimento médio de grãos de trigo da região de estudo. As variáveis significativamente correlacionadas com o rendimento (teste-t, 10\% de significância estatística) foram consideradas indicadores agrometeorológicos e espectrais do rendimento de grãos de trigo, desde que a 
correlação pudesse ser explicada com base na fisiologia da planta e nas características do ciclo de desenvolvimento da cultura. Foi realizada uma análise de trilha das variáveis escolhidas como indicadores agrometeorológicos e espectrais do rendimento de trigo. A análise de trilha mede a influência de uma variável sobre a outra, no contexto da relação de causa e efeito, desdobrando os coeficientes de correlações em seus efeitos diretos e indiretos (Vieira et al., 2007). Neste trabalho, a análise de trilha foi realizada no programa computacional Genes.

Os indicadores agrometeorológicos e espectrais foram considerados as variáveis independentes, na construção de uma equação de regressão linear múltipla de estimativa de rendimento de grãos de trigo. Na construção da regressão linear múltipla foram empregados apenas os dados referentes aos anos com disponibilidade da variável espectral, ou seja, de 2000 a 2006 . A construção da regressão linear múltipla foi realizada no pacote estatístico do programa computacional Excel.

A estabilidade das regressões lineares múltiplas foi avaliada mediante análise de possíveis alterações do coeficiente de determinação. Para isso, foram comparados os coeficientes de determinação das regressões elaboradas com a série completa de dados (2000 a 2006) com os coeficientes de determinação das regressões construídas com dados de seis anos (a cada rodada, um dos anos era retirado da série).

\section{RESULTADOS E DISCUSSÃO}

O rendimento médio de grãos de trigo da região de estudo, de 1990 a 2006 (Figura 1), foi de 1.860 kg.ha-1, valor superior à média do Estado $\left(1.570 \mathrm{~kg} \cdot \mathrm{ha}^{-1}\right)$, no mesmo período. Foi verificada variação interanual no rendimento, com diferença de $1.156 \mathrm{~kg} \cdot \mathrm{ha}^{-1}$ entre o ano de maior (2003) e menor (1997) rendimento. A variação interanual dos rendimentos pode ser decorrente das condições meteorológicas ou da incorporação de novas tecnologias.

O teste para verificação de tendência tecnológica mostrou que não houve significância no incremento anual de rendimento de grãos de trigo $(b=5,74)$, na região de estudo, no período analisado. Cunha et al. (1999), por sua vez, verificaram a existência de tendência tecnológica no rendimento de grãos de trigo do Estado do Rio Grande do Sul. Este resultado, no entanto, foi obtido pelos autores, empregando a série de dados de 1920 a 1997. A não existência de tendência tecnológica no rendimento de grãos da Cotrijal pode ser atribuída à consolidação das tecnologias de cultivo de trigo na região. Dado não ter ocorrido incremento anual significativo, as variações interanuais do rendimento de grãos podem ser atribuídas às variações das condições meteorológicas. Assim, foram utilizados, na construção da regressão linear múltipla, os valores originais de rendimento.

\section{Indicadores agrometeorológicos do rendimento de grãos de trigo}

$\mathrm{Na}$ Tabela 1, podem ser visualizadas algumas das variáveis agrometeorológicas e espectrais que foram significativamente correlacionadas com o rendimento de grãos de trigo da Cotrijal. Para escolha das variáveis a serem empregadas na construção da regressão linear múltipla, foi considerada a significância estatística da correlação, e, também, que a mesma pudesse ser adequadamente explicada com base na fisiologia da planta, no ciclo da cultura e no manejo das lavouras. Assim, foram escolhidas, como indicadores agrometeorológicos do rendimento de grãos de trigo, as seguintes variáveis: precipitação pluvial do mês de outubro, índice de dano por geadas (IG) e graus-dia.

A precipitação pluvial do mês de outubro foi considerada uma variável fundamental na definição do rendimento, em função da correlação $(-0,55)$ e do fato de que grãos formados em condições de excesso de precipitação pluvial (ou de maior número de dias com precipitação pluvial) apresentam baixo peso e qualidade, por causa da ocorrência de moléstias e de germinação pré-colheita (Guarienti et al., 2003; Bassoi, 2004), o que afeta negativamente o rendimento. É importante salientar que a precipitação pluvial acumulada nos períodos de maio a novembro e de junho a novembro também apresentaram correlação significativa (respectivamente, $-0,43$ e - 0,63 ) com o rendimento de grãos de trigo. Estas variáveis somente não foram escolhidas para comporem os dados de entrada da regressão linear múltipla em função de que a inclusão de informações referentes ao mês de colheita (novembro) acarretaria restrições de uso do modelo em programas de previsão de safras, já que o objetivo desses programas é, justamente, obter informações anteriores à data de colheita.

O índice de geadas (IG), embora não tenha sido significativamente correlacionado com o rendimento de grãos de trigo da Cotrijal, foi escolhido como uma das variáveis

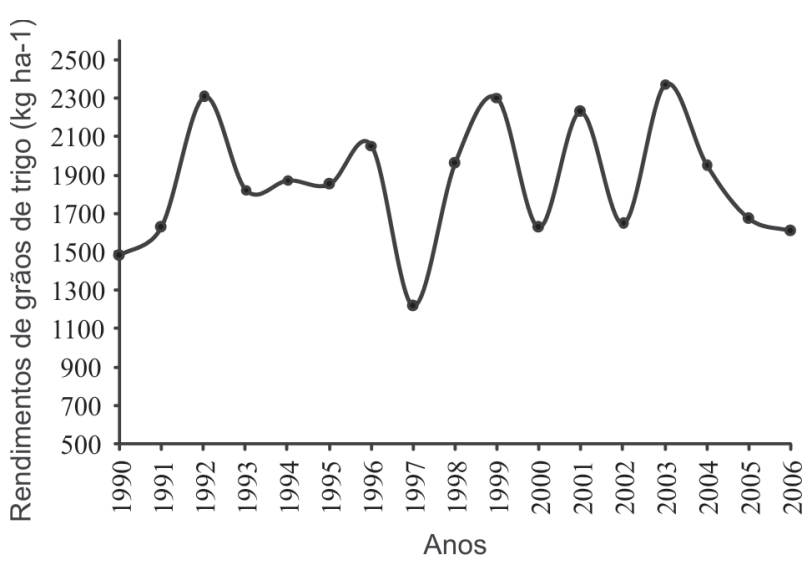

Figura 1. Rendimento médio de grãos de trigo $\left(\mathrm{kg} \mathrm{ha}^{-1}\right)$ da região de abrangência da Cotrijal (13 municípios localizados ao norte do Estado do Rio Grande do Sul) no período de 1990 a 2006. Fonte dos dados: IBGE (2007). 
de entrada da regressão linear múltipla. Tal escolha foi baseada nas perdas de safra ocorridas no ano de 2006, as quais foram associadas à ocorrência de geadas (Junges et al., 2008) De acordo com o IBGE, a produção brasileira de trigo, aveia branca e cevada, em 2006, registrou, comparativamente à safra anterior, redução de 45, 13 e 30\%, respectivamente, em virtude de, entre outros fatores, geadas ocorridas nos meses de agosto e setembro (IBGE, 2008). Sendo assim, com base na magnitude das perdas de rendimento da safra 2006, optou-se por considerar o IG um indicador agrometeorológico do rendimento de grãos de trigo. Foi escolhido o IG de setembro em função de que, na média dos anos de 2003 a 2006, 75\% da área plantada, na região de estudo, esteve em florescimento nesse mês. A escolha do IG de setembro corrobora o trabalho de Mota (1998), cujo modelo de estimativa de rendimento de grãos de trigo para o Rio Grande do Sul também empregou o índice de geadas de setembro.

Graus-dia (GD) acumulados de maio a novembro, junho a novembro e maio a outubro foram significativamente correlacionados com o rendimento de grãos de trigo da região de estudo, tanto calculados com temperatura basal de $0{ }^{\circ} \mathrm{C}$, quanto de $4,5^{\circ} \mathrm{C}$. As correlações negativas foram atribuídas ao fato de que elevadas temperaturas do ar (maior acúmulo de graus-dia) aceleram o ciclo de desenvolvimento das plantas, prejudicando o enchimento de grãos e, consequentemente, diminuindo o rendimento final da lavoura (Mundstock, 1999). Optou-se por empregar, como variável de entrada na regressão linear múltipla que define o modelo de estimativa de rendimento, os valores de graus-dia calculados com temperatura basal de 0 ${ }^{\circ} \mathrm{C}$ (simplificação de cálculo) e acumulados entre os meses de maio a outubro. Assim como no caso da variável precipitação pluvial, não foram incluídos os dados de graus-dia referentes ao mês de novembro.

\section{Indicadores espectrais do rendimento de grãos de trigo}

No que diz respeito às variáveis espectrais, a maior correlação destas com o rendimento de grãos de trigo da região de estudo foi obtida para o valor de NDVI integrado de junho a outubro (Tabela 1). De acordo com Rudorff \& Batista (1990), a integração do índice de vegetação representa a intensidade e a duração da atividade fotossintética da cultura, ao longo de seu ciclo de desenvolvimento, possuindo, assim, boa correlação com o rendimento final de grãos de trigo. Liu (2007) também empregou valores de NDVI, acumulados ao longo do período de crescimento, em modelos espectrais de estimativa de rendimento de grãos de milho em Ribeirão Preto, São Paulo. Assim, neste trabalho, o NDVI integrado de junho a outubro foi considerado indicador espectral do rendimento de grãos de trigo.

\section{Regressões lineares múltiplas de estimativa de rendimento de grãos de trigo}

Com as variáveis independentes precipitação pluvial do mês de outubro, índice de geadas de setembro e NDVI integrado de junho a outubro, foi construída uma equação de regressão linear múltipla de estimativa de rendimento de grãos de trigo (M1). Com o emprego dessas variáveis e dos graus-dia acumulados de maio a outubro, foi construída uma segunda equação, denominada M2.

As estimativas de rendimento dos modelos (M1 e M2) constam na Tabela 2. A equação de regressão linear múltipla (M1) apresentou coeficiente de determinação $\left(\mathrm{R}^{2}\right)$ de 0,83 e coeficiente de determinação ajustado de 0,67 , sendo assim definida:

$\mathrm{y}=-10265+(12,30 * N D V I)-(4,44 * I G)+(1,07 * P P)$

Tabela 1. Correlações entre os indicadores agrometeorológicos e espectrais e rendimento de grãos de trigo na região de abrangência da Cotrijal (13 municípios localizados ao norte do Estado do Rio Grande do Sul)

\begin{tabular}{|c|c|c|c|c|c|c|c|c|c|c|c|c|}
\hline \multirow{3}{*}{ Indicador } & \multicolumn{12}{|c|}{ Períodos } \\
\hline & \multicolumn{7}{|c|}{ Média Mensal } & \multicolumn{3}{|c|}{ Soma } & \multicolumn{2}{|c|}{ Integração } \\
\hline & Mai & Jun & Jul & Ago & Set & Out & Nov & $\mathbf{M N}^{(9)}$ & $\mathbf{J} \mathbf{N}^{(10)}$ & MO ${ }^{(11)}$ & $\mathbf{M N} \mathbf{N}^{(9)}$ & $\mathbf{J O}^{(12)}$ \\
\hline $\mathrm{PP}(\mathrm{mm})^{(1)}$ & 0,29 & $-0,46^{*}$ & 0,17 & $-0,42$ & 0,04 & $-0,55 * *$ & $-0,36$ & $-0,43^{*}$ & $-0,63 * *$ & $-0,37$ & - & - \\
\hline $\operatorname{UR}(\%)^{(2)}$ & 0,33 & 0,05 & 0,34 & $-0,04$ & $-0,05$ & $-0,45 * *$ & $-0,51 * *$ & - & - & - & - & - \\
\hline TMín $\left({ }^{\circ} \mathrm{C}\right)^{(3)}$ & $-0,22$ & $-0,01$ & $-0,25$ & $-0,35$ & 0,20 & $-0,46^{*}$ & $-0,56^{* *} *$ & - & - & - & - & - \\
\hline $\mathrm{N}^{\circ} \operatorname{diasPP} \mathrm{P}^{(4)}$ & 0,09 & $-0,56 * *$ & 0,04 & $-0,22$ & 0,17 & $-0,44 *$ & $-0,30$ & $-0,29$ & $-0,42$ & $-0,23$ & - & - \\
\hline $\mathrm{GD}\left(0^{\circ} \mathrm{C}\right)^{(5)}$ & $-0,33$ & 0,09 & $-0,35$ & $-0,39$ & 0,06 & $-0,28$ & $-0,40$ & $-0,52 * *$ & $-0,44^{*}$ & $-0,47 *$ & - & - \\
\hline $\mathrm{GD}\left(4,5^{\circ} \mathrm{C}\right)^{(6)}$ & $-0,26$ & 0,09 & $-0,35$ & $-0,41$ & 0,07 & $-0,28$ & $-0,40$ & $-0,49 *$ & $-0,45^{*}$ & $-0,46^{*}$ & - & - \\
\hline$Q^{(7)}$ & $-0,76$ & $-0,46$ & $-0,13$ & 0,33 & $-0,01$ & 0,45 & $0,57 * *$ & - & - & - & - & - \\
\hline $\mathrm{NDVI}^{(8)}$ & $-0,05$ & 0,13 & 0,41 & 0,61 & 0,38 & 0,23 & $-0,13$ & $0,68^{*}$ & $0,80 *$ & $0,78 *$ & $0,68^{*}$ & $0,83 * *$ \\
\hline
\end{tabular}

Indicadores: (1) Precipitação pluvial. (2) Umidade relativa do ar. (3) Temperatura mínima do ar. (4) Número de dias com precipitação pluvial. (5) Graus-dia calculados com a temperatura basal de $0^{\circ} \mathrm{C}$. (6) Graus-dia calculados com a temperatura basal de 4,5 ${ }^{\circ} \mathrm{C}$. (7) Quociente fototermal. (8) Índice de vegetação por diferença normalizada. Períodos: Soma de maio a novembro (9) e de junho a novembro (10). Integração de maio a outubro (11) e de junho a outubro (12). *Correlação significativa a $10 \%$ de probabilidade e **Correlação significativa a $5 \%$ de probabilidade. 
em que: NDVI é o Índice de Vegetação por Diferença Normalizada (integrado de junho a outubro), IG é o índice de geada (setembro) e PP é a precipitação pluvial (outubro).

A regressão linear múltipla $\mathrm{M} 2$ apresentou coeficiente de determinação $\left(\mathrm{R}^{2}\right)$ de 0,99 e de determinação ajustado de 0,99 , sendo assim definida:

$\mathrm{y}=-18929+(5,94 * \mathrm{NDVI})-(0,41 * \mathrm{IG})-(1,24 * \mathrm{PP})+$ $+(5,73 * \mathrm{GD}$

em que: NDVI é o Índice de Vegetação por Diferença Normalizada (integrado de junho a outubro), IG é o índice de geada (setembro) e PP é a precipitação pluvial (outubro) e GD são os graus-dia (acumulados de maio a outubro).

A maior diferença entre o rendimento oficial (IBGE) e o estimado ocorreu no modelo M1, no ano de 2001 (12,32\%). De modo geral, situações adversas ao adequado desenvolvimento das plantas, não relacionadas diretamente com as variáveis agrometeorológicas, podem ser monitoradas via NDVI, ou seja, pragas, moléstias e demais problemas relacionados com o manejo das lavouras provocam redução do indicador espectral e acabam, assim, sendo incluídas nos modelos de estimativa de rendimento. Em 2001, não foi observada uma diminuição dos valores de NDVI, comparativamente aos demais anos da série analisada, de modo que o erro de estimativa da regressão linear múlti- pla M1, neste ano, não esteve relacionado com o termo espectral do modelo.

Em 2001, as temperaturas do ar (média, máxima e mínima) no mês de agosto foram $2,5^{\circ} \mathrm{C}$ superiores à Normal Climatológica de Passo Fundo, e a precipitação pluvial foi de apenas $28 \mathrm{~mm}$ (Normal de $166 \mathrm{~mm}$ ), provocando déficit hídrico na região. As altas temperaturas e a escassa precipitação pluvial podem ter afetado as plantas no final do desenvolvimento vegetativo e, ou, início do florescimento. Cunha (2002) registrou que, no inverno de 2001, as temperaturas amenas aceleraram o ciclo de desenvolvimento das plantas de trigo, durante a fase vegetativa e, durante a fase reprodutiva, as estiagens foram responsáveis pela morte de afilhos e por dificuldades, em algumas lavouras, da aplicação da adubação nitrogenada em cobertura.

O coeficiente de regressão parcial da precipitação pluvial foi positivo, na equação M1, o que não era esperado em função de esta variável ser negativamente correlacionada com o rendimento de grãos (Tabela 1). A análise de trilha indicou que o efeito da precipitação pluvial no rendimento foi indireto e, basicamente, via NDVI (Tabela 3). Nesse caso, o aumento da precipitação pluvial pode ter ocasionado redução dos valores de NDVI, a qual acarretou um menor rendimento de grãos (efeito indireto). Por sua vez, o efeito direto da precipitação pluvial sobre o rendimento de grãos foi menor $(0,35)$ e positivo, levando a um coeficiente também positivo.

Tabela 2. Resultados da estimativa de rendimento de grãos de trigo por modelos agrometeorológicos-espectrais, na região de abrangência da Cotrijal (13 municípios localizados ao norte do Estado do Rio Grande do Sul)

\begin{tabular}{|c|c|c|c|c|c|c|c|c|}
\hline & & 2000 & 2001 & 2002 & 2003 & 2004 & 2005 & 2006 \\
\hline & & \multicolumn{7}{|c|}{ Rendimentos (kg.ha-1) } \\
\hline & IBGE & 1.628 & 2.229 & 1.645 & 2.374 & 1.946 & 1.671 & 1.607 \\
\hline \multirow{2}{*}{$\bar{\Sigma}$} & Modelo & 1.654 & 1.954 & 1.764 & 2.427 & 2.023 & 1.654 & 1.624 \\
\hline & Diferença $(\%)^{*}$ & $-1,57$ & 12,32 & $-7,23$ & $-2,25$ & $-3,96$ & 1,00 & $-1,01$ \\
\hline \multirow{2}{*}{$\tilde{\tilde{Z}}$} & Modelo & 1.621 & 2.231 & 1.651 & 2.370 & 1.951 & 1.670 & 1.606 \\
\hline & Diferença $(\%) *$ & 0,47 & $-0,09$ & $-0,35$ & 0,18 & $-0,29$ & 0,01 & 0,08 \\
\hline
\end{tabular}

* Diferença $(\%)=$ Rendimento de grãos oficial menos rendimento de grãos modelado.

${ }^{1}$ Variáveis independentes (M1): NDVI, IG (setembro), precipitação pluvial (outubro).

${ }^{2}$ Variáveis independentes (M2): NDVI, IG (setembro), precipitação pluvial (outubro) e graus-dia (maio a outubro).

Tabela 3. Análise de trilha dos indicadores agrometeorológicos-espectrais do rendimento de grãos de trigo, na região de abrangência da Cotrijal (13 municípios localizados ao norte do Estado do Rio Grande do Sul)

\begin{tabular}{|c|c|c|c|c|c|c|c|}
\hline \multirow{2}{*}{ Efeito } & \multicolumn{3}{|c|}{ Regressão linear múltiplaM1 } & \multicolumn{4}{|c|}{ Regressão linear múltipla M2 } \\
\hline & $\mathbf{N D V I}^{(1)}$ & $\mathbf{I G}^{(2)}$ & $\mathbf{P P}^{(3)}$ & NDVI & IG & PP & $\mathbf{G D}\left(\mathbf{0}^{\circ} \mathbf{C}\right)^{(4)}$ \\
\hline Direto sobre rendimento & 1,04 & $-0,11$ & 0,35 & 0,50 & $-1,05$ & $-0,41$ & 0,77 \\
\hline Indireto via NDVI & - & $-0,01$ & $-0,60$ & - & $-0,00$ & $-0,29$ & 0,05 \\
\hline Indireto via IG & 0,00 & - & 0,06 & 0,01 & - & 0,60 & $-0,67$ \\
\hline Indireto via PP & $-0,21$ & $-0,20$ & - & 0,24 & $-0,23$ & - & 0,045 \\
\hline Indireto via $\mathrm{GD}\left(0^{\circ} \mathrm{C}\right)$ & - & - & - & 0,08 & 0,49 & $-0,09$ & - \\
\hline Total & 0,83 & $-0,33$ & $-0,18$ & 0,83 & $-0,33$ & $-0,18$ & 0,20 \\
\hline
\end{tabular}

(1) Índice de Vegetação por Diferença Normalizada (integrado de junho a outubro); (2) Índice de Geada (setembro); (3) Precipitação pluvial (outubro); (4) Graus-dia calculados com a temperatura basal de $0^{\circ} \mathrm{C}$ (acumulados de maio a outubro). 
É importante salientar que, inicialmente, a construção de regressões lineares múltiplas, empregando variáveis espectrais, buscou construir modelos de estimativa de rendimento baseados na penalização do indicador espectral NDVI, quando da ocorrência de elementos meteorológicos adversos ao desenvolvimento das plantas e com reais implicações na definição de rendimento final de grãos. O modelo M1 representou, justamente, esse conceito simples de modelo de estimativa. Posteriormente, em uma segunda regressão linear múltipla, foi incluído, como variável independente, o indicador graus-dia acumulados de maio a outubro. A variável graus-dia não buscou, ao contrário das variáveis precipitação pluvial e índice de geada, penalizar o NDVI, mas, caracterizar, junto com o índice, o ciclo de crescimento e desenvolvimento das plantas de trigo.

A introdução do indicador agrometeorológico grausdia melhorou o desempenho do modelo. A análise de trilha das variáveis empregadas na definição da equação M2 (Tabela 3) mostrou que o efeito direto dos graus-dia, acumulados de maio a outubro, no rendimento final de grãos, foi o maior dentre as variáveis analisadas.

Ambas as regressões lineares múltiplas (M1 e M2) foram consideradas adequadas à estimativa de rendimento de grãos de trigo, na região da Cotrijal. Em somente um dos anos estudados, o erro da estimativa da regressão linear múltipla M1 foi superior a 10\%. No presente estudo, este foi considerado um bom resultado, tendo em vista que erros de até $20 \%$, em modelos espectrais de estimativa de rendimento de grãos de trigo, foram citados por Liu (2007).

$\mathrm{Na}$ análise de estabilidade dos modelos, os valores dos coeficientes de determinação da regressão M1 variaram de $\mathrm{R}^{2}=0,73$ (quando não incluídos os dados referentes a 2003) a $R^{2}=0,98$ (quando não incluídos os dados referentes a 2001). Os valores dos coeficientes de determinação da regressão M2 não sofreram alterações. Apesar da reduzida série de dados empregada na construção das regressões lineares múltiplas que definem os modelos (M1 e M2), as estimativas de rendimento foram consideradas consistentes e próximas aos dados oficiais ( $\mathrm{Fi}-$ gura 2).

Assim, as equações de regressão linear múltipla, construídas com dados agrometeorológicos e espectrais, contribuem para geração de informações que, aliadas às estatísticas oficiais, podem qualificar os sistemas de previsão de safras. Além disso, as informações podem ser obtidas com características de precisão, fácil execução e baixo custo. No entanto, em função das equações de regressão linear múltipla terem sido construídas com uma série de dados de apenas sete anos, mais estudos são necessários para verificação dos resultados das estimativas, quando da incorporação de uma série maior de da-
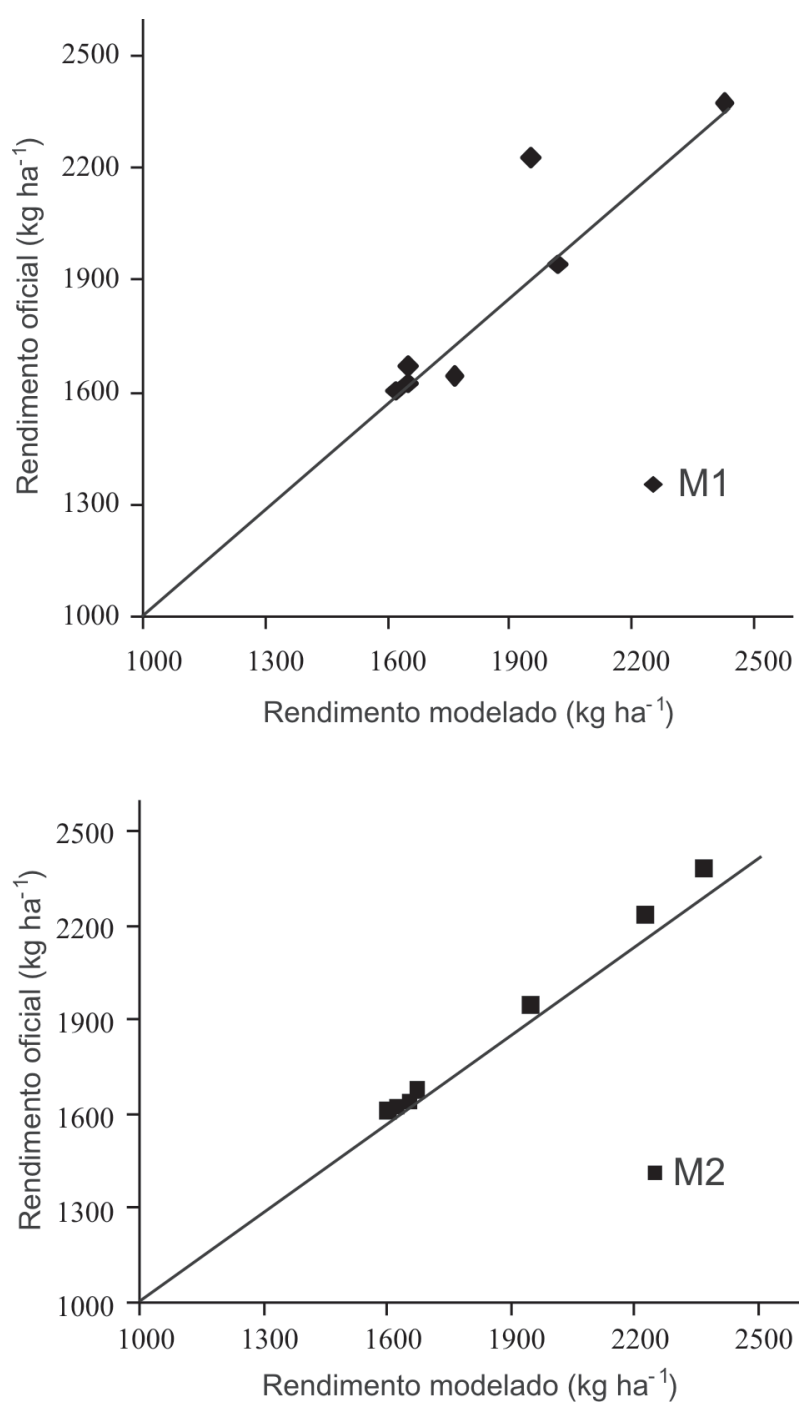

Figura 2. Relação entre rendimento de grãos de trigo $\left(\mathrm{kg} \mathrm{ha}^{-1}\right)$ oficial e estimado pelas equações de regressão linear múltipla M1 (variáveis independentes NDVI, índice de geada de setembro e precipitação pluvial de outubro) e M2 (variáveis independentes NDVI, índice de geada de setembro, precipitação pluvial de outubro e graus-dia acumulados de maio a outubro), de 2000 a 2006, na região de abrangência da Cotrijal (13 municípios localizados ao norte do Estado do Rio Grande do Sul).

dos. Nesse sentido, estudos futuros podem ser conduzidos com um maior número de imagens MODIS e, ou, com a ampliação da área de estudo.

\section{CONCLUSÕES}

Equações de regressão linear múltipla, construídas a partir de indicadores agrometeorológicos (precipitação pluvial, índice de geadas e graus-dia) e espectrais (NDVI), caracterizam de forma adequada as condições ambientais e seus efeitos na definição do rendimento final de lavouras de trigo, na região de atuação da Cotrijal, podendo, assim, ser empregadas na estimativa desta variável. 


\section{REFERÊNCIAS}

Bassoi MC (2004) Aspectos gerais da germinação pré-colheita e seu controle genético. In: Cunha G. Germinação pré-colheita em trigo. Passo Fundo, EMBRAPA Trigo. p.23-45.

Braga HJ (1995) Previsão agrícola: uma nova abordagem-uso de scanner aerotransportável e redes neurais. Tese de Doutorado Florianópolis, Universidade Federal de Santa Catarina, 197p.

Carmona LC \& Berlato MA (2002) Relação entre elementos meteorológicos e rendimento do arroz irrigado no Estado do Rio Grande do Sul. Revista Brasileira de Agrometeorologia, 10:289-294.

Cunha GR, Dalmago GA \& Estefanel V (1999) Enso influences on wheat crop in Brazil. Revista Brasileira de Agrometeorologia, $7: 127-138$

Cunha GR (2002) Clima e cevada cervejeira no Brasil: análise da safra 2001 e perspectivas climáticas para a safra 2002. In: 22a Reunião Anual de Pesquisa de Cevada, Passo Fundo. Anais e Ata, EMBRAPA Trigo. p.27-37.

Cunha GR, Pires JLF, Pasinato A \& Dalmago GA (2005) Variabilidade temporal e espacial do quociente fototermal no Rio Grande do Sul e suas implicações para a expressão do potencial de rendimento de grãos de trigo. Revista Brasileira de Agrometeorologia, 13:91-101.

Deppe F, Lohmann M, Martini L, Adami M \& Faria R (2007) Monitoramento da evolução temporal de cultivos agrícolas através de imagens TERRA/MODIS. In: $13^{\circ}$ Simpósio Brasileiro de Sensoriamento Remoto, Florianópolis. Anais, INPE. p.145-152.

Fontana DC, Potgieter AB \& Apan A (2007) Assessing the relationship between shire winter crop yield and seasonal variability of the MODIS NDVI and EVI images. Applied GIS, 3:1-16.

Fronza V, Campos LAC \& Riede CR (Org.) (2008) Reunião da Comissão Brasileira de Pesquisa de Trigo e Triticale - Informações técnicas para safra 2008: trigo e triticale. Londrina, Embrapa Soja. 147p.

Guarienti EM, Ciacco CF, Cunha GR, Duca LJD \& Camargo CMO (2003) Avaliação do efeito de variáveis meteorológicas na qualidade industrial e no rendimento de grãos de trigo pelo emprego de análise dos componentes principais. Ciência e Tecnologia de Alimentos, 23:500-510

Huete AR, Didan K, Miura T, Rodriguez EP, Gao X \& Ferreira LG (2002) Overview of the radiometric and biophysical performance of the MODIS vegetation index. Remote Sensing of Environment, 83:195-213.

IBGE (2007) Levantamento sistemático da produção agrícola. Disponível em: <http://www.sidra.ibge.gov.br> Acessado em: 31 de janeiro de 2011.

IBGE (2008) Últimas notícias. Disponível em: <http:// www.ibge.gov.br/home/ presidencia/noticias> Acessado em: 31 de janeiro de 2011.
Junges AH, Gusso A, Melo RW \& Fontana DC (2008) Avaliação das perdas de rendimento de trigo na safra 2006 por meio das análises de temperaturas mínimas do ar e de superfície na região norte do Rio Grande do Sul. Revista Brasileira de Agrometeorologia, 16:1-8.

Klering EV (2007) Avaliação do uso de imagens MODIS na modelagem agrometeorológica-espectral de rendimento do arroz irrigado no Rio Grande do Sul. Dissertação de Mestrado. Porto Alegre, Universidade Federal do Rio Grande do Sul, 116p.

Köppen W (1948) Climatologia. México, DF, Fondo de Cultura Economica. $71 \mathrm{p}$.

Liu WTH (2007) Previsão de safra agrícola. In: Liu WHT. Aplicações de sensoriamento remoto. $1^{\mathrm{a}}$ ed. Campo Grande, Uniderp. p.561-649.

Melo RW, Fontana DC, Berlato MA \& Ducati JR (2008) An agrometeorological-spectral model to estimate soybean yield, applied to southern Brazil. International Journal of Remote Sensing, 29:4013-4028.

Moreira LF (2008) Multicolinearidade em análise de regressão. In: $12^{\circ}$ Encontro Regional de Matemática Aplicada e Computacional, Foz do Iguaçu. Anais, Unioeste. p.61-75.

Mota F (1998) Influência do clima sobre o rendimento de trigo no Rio Grande do Sul. Revista Brasileira de Agrometeorologia, 6:121-124.

Mundstock CM (1999) Planejamento e manejo integrado da lavoura de trigo. $3^{\mathrm{a}}$ ed. Porto Alegre, Evangraf. 227p.

Rizzi R (2004) Geotecnologias em um sistema de estimativa da produção de soja: estudo de caso no Rio Grande do Sul. Tese de Doutorado. São José dos Campos, Instituto Nacional de Pesquisas Espaciais, 212p.

Rosa VGC (2007) Modelo agrometeorológico-espectral para monitoramento e estimativa de rendimento do café na região sul/sudoeste do Estado de Minas Gerais. Dissertação de Mestrado. São José dos Campos, Instituto Nacional de Pesquisas Espaciais, 142 p.

Rudorff BFT \& Batista GT (1990) Spectral response of wheat and its relationship with agronomic variables in the tropical region. Remote Sensing of Environment, 31:53-63.

Sugawara L (2001) Avaliação de modelo agrometeorológico e de imagens NOAA/AVHRR no acompanhamento e estimativa de rendimento da soja no Estado do Paraná. Dissertação Mestrado. São José dos Campos, Instituto Nacional de Pesquisas Espaciais, $181 \mathrm{p}$.

Vieira EA, Carvalho FIF, Oliveira AC, Martins LF, Benin G, Silva JAG, Coimbra JLM, Martins AF, Carvalho MF \& Ribeiro G (2007) Análise de trilha entre os componentes primários e secundários do rendimento de grãos em trigo. Revista Brasileira de Agrociência, 13:169-174. 